\title{
PERENCANAAN ARSITEKTUR SISTEM INFORMASI KEIMIGRASIAN PADA PLBN TERPADU DI NTT
}

\author{
Fransiskus Mario Hartono Tjiptabudi \\ Program Studi Sistem Informasi, STIKOM Uyelindo Kupang \\ email: tjiptabudifrans@gmail.com
}

\begin{abstract}
Useful information system to support of business process an organization/company with no eception immigration authority. Business process that so far has been implemented have not use information technology maximally resulted in a fall in the passer the limits for the low service quality to the unfixed data storage and difficulty for finding data and produce reports. The purpose of the research are to design a cross platform information system architecture to support the business process carried out by the immigration authorities on three (3) Integrated Cross Border Posts (PLBN) under the control of the Class II Immigration Office of Atambua, East Nusa Tenggara. For the purposes of the architecture planning was using the framework of TOGAF ADM based on mapped problems, while the design of the information system is based on the PIECES framework. Information systems that proposed aims to solve the problems faced by and to support policy and the government's national strategies in the management of the border region. It is expected that the design of cross platform information system applied to linking immigration offices, immigration officers in PLBN and the passer. The results of this research are expected to be implemented in support of the business process on the immigration authorities with linking immigration offices, immigration officers in PLBN and the passer and also to improve the services of the immigration officer.
\end{abstract}

Keywords: information systems, business process, TOGAF ADM, PIECES.

\section{PENDAhuluan}

Saat ini teknologi informasi telah sangat berkembang dan menjadi kebutuhan penting. Tidak dapat dipungkiri bahwa teknologi informasi telah mempengaruhi segala sektor, mulai dari sektor pemerintahan, perbankan, hingga pendidikan. Seperti yang diketahui, pada dekade terakhir ini penggunaan teknologi informasi dan komunikasi dalam organisasi pemerintahan maupun swasta telah menjadi sebuah kebutuhan. Pada sektor swasta, teknologi informasi diterapkan untuk mencapai tujuan bisnis strategis dan menciptakan keunggulan kompetitif [1]; [2], sedangkan pada organisasi pemerintah teknologi informasi diterapkan untuk berbagai arah kepentingan secara bersamaan [3] dan tunduk pada tujuan kompetitif [4].

Pada penelitian ini mengambil studi kasus pada layanan keimigrasian yang dilaksanakan oleh otoritas imigrasi pada tiga (3) Pos Lintas Batas Negara (PLBN) Terpadu di Nusa Tenggara Timur yaitu PLBN Terpadu Mota'ain, PLBN Terpadu Motamasin dan PLBN Terpadu Wini. Proses bisnis yang dilakukan selama ini memiliki berbagai permasalahan yang disebabkan oleh model administrasi yang belum memanfaatkan teknologi informasi secara maksimal. Adapun model administrasi yang dilakukan adalah dengan cara para pelintas menulis data paspor atau Pas Lintas Batas (PLB) serta data transaksi pada sebuah kartu yang kemudian akan direkapitulasi oleh petugas imigrasi setiap harinya. Model tersebut tentu merepotkan para pelintas, belum lagi jika para pelintas adalah orang yang kemampuan literasi baca-tulisnya rendah maka tentu sangat merepotkan. Selain itu, ketidakrapian penyimpanan data transaksi menyebabkan kesulitan pencarian data, penyajian laporan kepada atasan hingga pengontrolan lama izin tinggal. Otoritas imigrasi sebagai salah satu unit kerja pada PLBN Terpadu memiliki tanggung jawab antara lain mengawasi lalu lintas orang yang keluar/masuk wilayah Indonesia dan memberikan pelayanan kepada masyarakat, merasa perlu menerapkan teknologi informasi guna meningkatkan kualitas dalam melaksanakan tugas tersebut [5]. 
Infrastruktur teknologi informasi/sistem informasi merupakan investasi yang besar dalam organisasi/perusahaan. Banyaknya dana yang dikeluarkan dirasakan berat untuk menyediakannya. Sering terjadi dalam suatu investasi yang besar tidak diiringi dengan manfaat yang dirasakan bahkan kerugian bagi organisasi/perusahaan. Penyebab utama dari kegagalan adalah kurangnya perencanaan yang matang terhadap implementasi sistem informasi/teknologi informasi [6]. Oleh karena itu dengan perencanaan infrastruktur dan perancangan sistem informasi yang tepat diharapkan dapat meminimalkan atau bahkan meniadakan kerugian organisasi/perusahaan.

Sebelumnya telah dilakukan beberapa penelitian yang relevan antara lain oleh [7] yang menyatakan bahwa perancangan yang matang dalam implementasi sistem mutlak diperlukan untuk mencegah kegagalan dan penghamburan biaya saat implementasi sistem dan implementasi sistem tersebut dapat mempermudah dan mempercepat pelayanan terhadap semua stakeholder. Selain itu, [8] mengemukakan bahwa dampak dari perancangan arsitektur TI terhadap proses bisnis Yakuza Gym adalah terciptanya efektifitas dan efisiensi dalam proses bisnisnya.

Perancangan yang dibahas pada penelitian ini adalah perancangan infrastruktur sistem informasi lintas platform (mobile dan komputer) guna memecahkan masalah yang dialami oleh otoritas imigrasi pada PLBN Terpadu di NTT berdasarkan kerangka PIECES dan TOGAF ADM. Kerangka PIECES digunakan untuk menganalisis permasalahan dan kebutuhan dilihat dari berbagai dimensi, sedangkan TOGAF ADM digunakan karena memiliki metode dan tools yang detail serta bersifat fleksibel dan open source [7]. Adapun tujuan yang hendak dicapai dalam penelitian ini yaitu untuk merancang infrastruktur sistem informasi bagi otoritas imigrasi di PLBN Terpadu di NTT guna mendukung proses bisnisnya dalam hal modernisasi administrasi dan peningkatan kualitas layanan.

\section{KAJIAN LITERATUR}

\subsection{Sistem Informasi}

Sistem informasi adalah suatu sistem di dalam suatu organisasi yang mempertemukan kebutuhan pengolahan transaksi harian yang mendukung fungsi operasi organisasi yang bersifat manajerial dengan kegiatan strategi dari suatu organisasi untuk dapat menyediakan kepada pihak luar tertentu dengan laporan-laporan yang diperlukan. [9]. Sistem informasi juga didefinisikan sebagai suatu sistem yang dibuat oleh manusia yang terdiri dari komponen-komponen dalam organisasi untuk menyajikan informasi [10].

Berdasarkan pengertian yang telah dipaparkan maka dapat disimpulkan bahwa sistem informasi merupakan gabungan dari manusia, hardware, software, jaringan komunikasi dan data yang saling berinteraksi untuk menyimpan, mengumpulkan, memproses, dan mendistribusikan informasi untuk mendukung pengambilan keputusan dalam suatu organisasi.

\subsection{PIECES Framework}

Teknik analisis ini dijelaskan oleh [11] untuk membuat sebuah sistem yang dibuat secara prototyping dengan melakukan analisa terlebih dahulu untuk mengetahui permasalahan dan kebutuhan untuk membuat sistem. Sebuah sistem perlu ditemukan permasalahan yang ada agar sistem dapat berjalan dengan baik dan bisa mencapai tujuan yang diharapkan. Adapun beberapa dimensi yang dapat dilihat dari analisis ini adalah sebagai berikut:

a. Performance (kinerja)

Diperlukan untuk menilai kinerja dari sistem yang terdiri dari:

1) Throughput: sistem dinilai dari banyaknya kerja (output) yang dilakukan pada beberapa periode waktu dalam memenuhi kebutuhan.

2) Respon time: waktu yang diperlukan oleh sistem informasi untuk melakukan proses kerja.

3) Audibilitas: keselarasan terhadap standar dapat diperiksa.

4) Kelaziman komunikasi: terkait user interface yang digunakan dalam sistem informasi dinilai dalam kemudahan untuk dipahami.

5) Kelengkapan: derajat dimana sistem informasi mempunyai fungsi yang penuh dalam mendukung pekerjaan.

6) Toleransi kesalahan: kerusakan yang terjadi pada saat program mengalami kesalahan.

b. Information and data (informasi dan data) 
Diperlukan untuk menilai informasi yang dihasilkan dan data yang digunakan, terdiri dari:

1) Accuracy (akurat): informasi atas hasil evaluasi hendaklah memiliki tingkat ketepatan/ketelitian yang tinggi.

2) Relevansi informasi: informasi yang dihasilkan sesuai dengan kebutuhan.

3) Penyajian informasi: informasi disajikan dalam bentuk yang sesuai.

4) Aksesibilitas informasi: informasi dapat tersedia sewaktu-waktu ketika dibutuhkan.

c. Economic (ekonomi)

Diperlukan untuk menilai sistem informasi dari aspek ekonomi yang terdiri dari:

1) Reusabilitas: tingkat dimana sebuah program atau bagian dari program tersebut dapat digunakan kembali di dalam aplikasi yang lain.

2) Sumber daya: sumber daya yang digunakan dalam pengembangan sistem, meliputi sumber daya manusia serta sumber daya ekonomi.

d. Control and security (kontrol dan keamanan)

Digunakan untuk menilai sistem informasi dari aspek keamanan dan kontrol data yang terdiri dari:

1) Integritas: tingkat dimana akses ke perangkat lunak atau data oleh orang yang tidak berhak dapat dikontrol.

2) Keamanan: mekanisme yang mengontrol atau melindungi program dan data dalam sistem informasi.

e. Efficiency (efisiensi)

Digunakan untuk menilai sistem informasi dari aspek efisiensi yang terdiri dari:

1) Usabilitas: usaha yang dibutuhkan untuk mempelajari, mengoperasikan, menyiapkan input, dan menginterpretasikan output suatu program.

2) Maintanabilitas: usaha yang diperlukan untuk mencari dan membetulkan kesalahan pada sebuah program.

f. Service (pelayanan)

Digunakan untuk mengetahui bagaimana meningkatkan kepuasan pelanggan, pegawai dan manajemen. Aspek service (pelayanan) terdiri dari:

1) Akurasi: ketelitian komputasi dan kontrol.

2) Reliabilitas: tingkat dimana sebuah program dapat dipercaya dan diandalkan untuk melakukan fungsi yang diminta.

3) Kesederhanaan, yaitu tingkat dimana sebuah program dapat dipahami tanpa kesukaran.

\subsection{TOGAF ADM}

Technical Open Group Architecture Framework (TOGAF), merupakan kerangka kerja untuk pengembangan arsitektur perusahaan, diusulkan oleh The Open Group (2009) dan berdasarkan prakarsa DOD AS TOGAF pada tahun 1995. Versi awal TOGAF didasarkan pada Technical Architecture Framework for Information Management (TAFIM), yang dikembangkan oleh Department of Defense U.S. (DoD) [12] namun pada perkembangannya TOGAF banyak digunakan pada berbagai bidang seperti perbankan, industri manufaktur dan juga pendidikan. TOGAF digunakan untuk mengembangkan Enterprise Architecture (EA), dimana terdapat metode dan tools yang detil untuk mengimplementasikannya. Salah satu kelebihan menggunakan kerangka TOGAF ini adalah karena sifatnya yang fleksibel dan bersifat open source (The [13]. TOGAF juga memungkinkan arsitek dan pemangku kepentingan perusahaan merancang, mengevaluasi, dan membangun arsitektur perusahaan yang fleksibel bagi organisasi [12].

TOGAF memberikan metode yang detil bagaimana membangun dan mengelola serta mengimplementasikan arsitektur enterprise dan sistem informasi yang disebut dengan Architecture Development Method (ADM).

ADM memberikan gambaran spesifik untuk proses pengembangan arsitektur [14]. ADM merupakan bagian utama dari TOGAF yang memberikan gambaran rinci bagaimana menentukan sebuah enterprise architecture secara spesifik berdasarkan kebutuhan bisnisnya. Pendapat lain juga menyatakan bahwa ADM merupakan metode generik yang berisikan sekumpulan aktivitas yang digunakan dalam memodelkan pengembangan arsitektur enterprise. Metode ini juga bisa digunakan sebagai panduan atau 
alat untuk merencanakan, merancang, mengembangkan dan mengimplementasikan arsitektur sistem informasi untuk organisasi [15].

Berdasarkan pendapat-pendapat yang telah dikemukakan,dapat disimpulkan bahwa TOGAF ADM diartikan sebagai seperangkat alat yang digunakan untuk mengembangkan EA dari tahapan mendesain, membangun dan mengevaluasi secara spesifik berdasarkan kebutuhan bisnis. Gambar berikut menunjukkan tahapan proses arsitektur menggunakan TOGAF ADM.

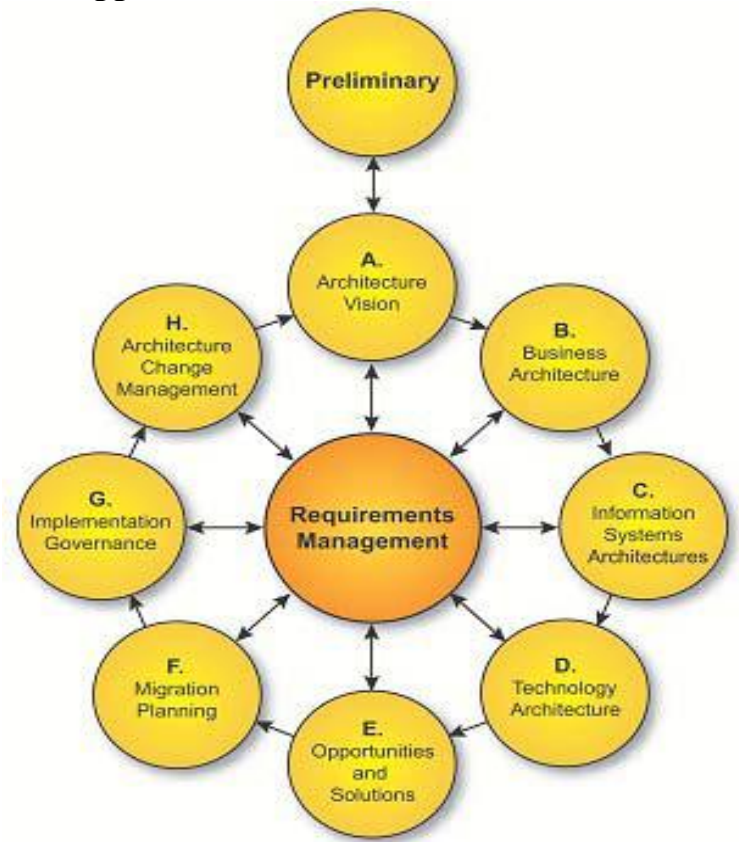

Sumber : The Open Group, 2009

\section{Gambar 1. Kerangka TOGAF ADM}

Berikut ini adalah penjelasan dari masingmasing fase pada TOGAF ADM menurut The Open Group (2009).

\section{a. Preliminary Phase}

Tahapan persiapan (preliminary phase) merupakan tahap awal persiapan perancangan enterprise architecture.

\section{b. Requirements Management}

Requirements management adalah proses pengelolaan kebutuhan arsitektur di seluruh fase TOGAF ADM.

c. Phase A: Architecture Vision

Phase architecture vision atau fase visi arsitektur adalah mendefinisikan scope, vision dan memetakan strategi keseluruhan.

d. Phase B: Business Architecture
Phase business architecture atau fase arsitektur bisnis berisi strategi bisnis, organisasi, dan informasi aktivitas utama

e. Phase $C$ : Information Systems

Architecture

Phase Information System Architecture adalah mengembangkan arsitektur sasaran untuk data dan aplikasi.

f. Phase D: Technology Architecture

Phase Technology Architecture untuk menciptakan sasaran keseluruhan arsitektur yang akan diterapkan pada tahapan ke depan.

g. Phase E: Opportunities and Solutions

Phase Opportunities and Solutions yaitu fase mengembangkan strategi keseluruhan, menentukan apa yang akan dibeli, membangun atau penggunaan ulang, dan bagaimana menerapkan arsitektur yang dideskripsikan di phase $D$.

h. Phase F: Migration Planning

Fokus utama dari phase migration planning atau fase rencana migrasi adalah penciptaan rencana implementasi dan migrasi yang layak, bekerja sama dengan portofolio dan manajer proyek.

i. Phase G: Implementation Governance

Pada Phase implementation governance atau fase tata kelola implementasi, proyek dilaksanakan sebagai program rencana kerja dan diolah agar dapat mencapai arsitektur yang diinginkan.

j. Phase H: Architecture Change

Management

Pada phase architecture change management atau fase manajemen perubahan arsitektur akan diuraikan penggerak perubahan dan bagaimana mengatur perubahan tersebut, mulai dari pemeliharaan sederhana sampai perancangan kembali arsitektur.

Semua komponen TOGAF ini menghasilkan kiriman dalam bentuk diagram, diagram alir, struktur, definisi dan artefak lainnya [16].

\section{METODE PENELITIAN}

Permasalahan yang dialami oleh otoritas imigrasi pada PLBN Terpadu di NTT akan diselesaikan dengan perancangan arsitektur sistem informasi dengan berpatokan pada kerangka PIECES dan TOGAF ADM.

Permasalahan-permasalahan yang dihadapi oleh pihak otoritas imigrasi dalam 
menjalankan proses bisnisnya serta kebutuhan-kebutuhan apa saja yang harus disiapkan mulai dari aspek manusia, software dan hardware dianalisis berdasarkan enam (6) dimensi pada kerangka PIECES yaitu performance, information and data, economic, control and security, efficiency dan service.

Setelah permasalahan dan kebutuhan telah dianalisis berdasarkan kerangka PIECES maka langkah selanjutnya adalah merencanakan arsitektur sistem informasinya dengan menerapkan TOGAF ADM. Untuk perencanaan arsitektur sistem informasi pada penelitian ini hanya sampai pada Phase D: Technology Architecture atau tahap menentukan arsitektur teknologi yang dibutuhkan untuk sistem informasi yang baru. Hal tersebut disebabkan oleh beberapa hal sebagai berikut:

a. Belum adanya kebijakan guna melakukan migrasi ke sistem yang baru.

b. Belum adanya kesiapan untuk perubahan manajemen berdasarkan rencana yang ditawarkan.

Adapun skema penelitian yang akan dilakukan dapat dilihat pada gambar 2 .

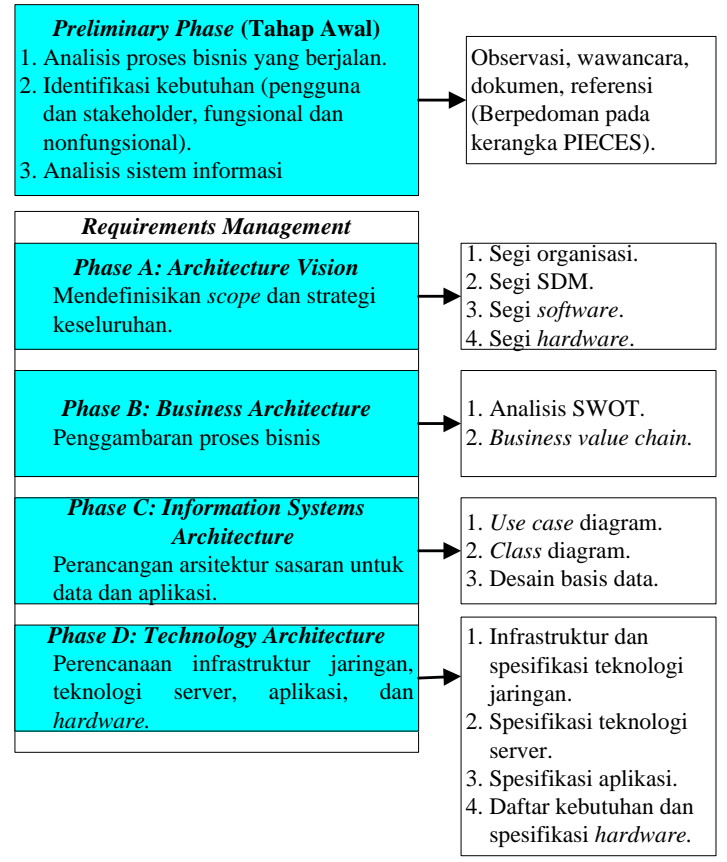

Gambar 2. Skema penelitian

\section{HASIL DAN PEMBAHASAN}

\subsection{Hasil Analisis Permasalahan}

Adapun hasil dari tahap analisis permasalahan pada proses bisnis yang dilaksanakan oleh otoritas imigrasi pada tiga (3) PLBN Terpadu di wilayah NTT dapat dilihat pada tabel 1 berikut:

Tabel 1. Hasil analisis berdasarkan kerangka PIECES

\begin{tabular}{|c|c|c|}
\hline No. & Dimensi & Permasalahan \\
\hline \multirow[t]{4}{*}{1.} & Performance & 1. Waktu yang dibutuhkan untuk melayani pelintas batas lama. \\
\hline & & 2. Model pelayanan cenderung merepotkan pelintas batas. \\
\hline & & 3. Pendataan tidak rapi. \\
\hline & & 4. Penyimpanan data konvensional. \\
\hline \multirow[t]{2}{*}{2.} & Information & 1. Belum adanya basis data. \\
\hline & and data & $\begin{array}{l}\text { 2. Sulit mencari informasi, menghasilkan laporan dan mengontrol izin } \\
\text { tinggal. }\end{array}$ \\
\hline 3. & Economic & Pemborosan kertas karena model administrasi based on paper. \\
\hline \multirow[t]{3}{*}{4.} & Control and & 1. Integritas data rendah. \\
\hline & security & 2. Tidak ada keamanan data. \\
\hline & & 3. Sulit mengontrol izin tinggal. \\
\hline \multirow[t]{2}{*}{5.} & Efficiency & $\begin{array}{l}\text { 1. Membutuhkan jumlah petugas yang banyak jika terjadi antrian pelintas } \\
\text { batas. }\end{array}$ \\
\hline & & $\begin{array}{l}\text { 2. Proses kerja tidak efisien karena terdiri dari tahapan yang berdiri } \\
\text { sendiri yaitu mendata, merekapitulasi dan menyusun laporan. }\end{array}$ \\
\hline \multirow[t]{2}{*}{6.} & Service & 1. Waktu pelayanan relatif lama. \\
\hline & & 2. Akurasi pendataan rendah. \\
\hline
\end{tabular}




\subsection{Perencanaan Arsitektur Sistem Informasi}

Berdasarkan hasil analisis permasalahan yang telah dijelaskan sebelumnya, maka diusulkan perencanaan arsitektur dengan beberapa tahapan sebagai berikut:

a. Menentukan visi arsitektur

Visi yang ingin dicapai pada penelitian ini adalah menghasilkan cetakbiru arsitektur sistem informasi pelintas batas wilayah negara (Sintaswin). Adapun cakupan dari sistem informasi ini adalah terdiri dari aplikasi pendataan paspor/PLB, aplikasi transaksi, aplikasi komunikasi dan aplikasi pemantauan yang tentunya membutuhkan hardware dengan spesifikasi yang mendukung jaringan client server.

Dari segi organisasi tidak menimbulkan perubahan secara struktur tetapi penambahan fungsi pemantauan (controlling) dan persetujuan (approve) bagi Kepala Kantor Imigrasi dan supervisor di PLBN.

b. Penggambaran proses bisnis

Penggambaran proses bisnis terdiri dari tahapan analisis SWOT dan penjelasan menggunakan rantai nilai bisnis.

Analisis SWOT digunakan sebagai dasar untuk merancang strategi bisnis yang mana analisis ini membandingkan kondisi internal meliputi faktor kekuatan (Strength) dan kelemahan (Weakness) serta kondisi eksternal mencakup faktor peluang (Opportunity) dan tantangan (Threats).

\begin{tabular}{|c|c|c|}
\hline Faktor Eksternal & $\begin{array}{l}\text { Kekuatan } \\
\text { 1. Fisik gedung } \\
\text { yang telah } \\
\text { diupgrade. } \\
\text { 2. Jumlah SDM } \\
\text { yang memadai. }\end{array}$ & $\begin{array}{l}\text { Kelemahan } \\
\text { 1. Sarana teknologi } \\
\text { masih minim. } \\
\text { 2. Kualitas SDM } \\
\text { bidang IT kurang. } \\
\text { 3. Model administrasi } \\
\text { konvensional. }\end{array}$ \\
\hline $\begin{array}{l}\text { Peluang } \\
\text { 1. Adanya program } \\
\text { pemerintah untuk } \\
\text { pengembangan } \\
\text { daerah perbatasan. } \\
\text { 2. Tingkat } \\
\text { penyeberangan } \\
\text { WNA \& WNI } \\
\text { meningkat. }\end{array}$ & \multirow{2}{*}{\multicolumn{2}{|c|}{$\begin{array}{l}\text { Jalan keluar: } \\
\text { 1. Peningkatan fasilitas } \\
\text { khususnya di bidang } \\
\text { teknologi informasi. } \\
\text { 2. Peningkatan kualitas SDM } \\
\text { melalui pelatihan. } \\
\text { 3. Modernisasi administrasi } \\
\text { berbasis sistem informasi } \\
\text { guna perbaikan layanan dan } \\
\text { meminimalisir pelanggaran } \\
\text { izin oleh para pelintas batas }\end{array}$}} \\
\hline $\begin{array}{l}\text { Ancaman } \\
\text { 1. Ketidakpuasan } \\
\text { para pelintas } \\
\text { terhadap } \\
\text { pelayanan. } \\
\text { 2. Meningkatnya } \\
\text { jumlah } \\
\text { pelanggaran izin } \\
\text { tinggal }\end{array}$ & & \\
\hline
\end{tabular}

Gambar 3. Hasil analisis SWOT

Berdasarkan hasil analisis SWOT, maka ditawarkan solusi seperti pada gambar 3, antara lain peningkatan fasilitas TIK dan kualitas SDM serta pemanfaatan teknologi informasi guna modernisasi administrasi. Oleh karena itu, rantai bisnis yang akan dijalankan setelah diimplementasi sistem informasi tersebut adalah seperti pada gambar 4.

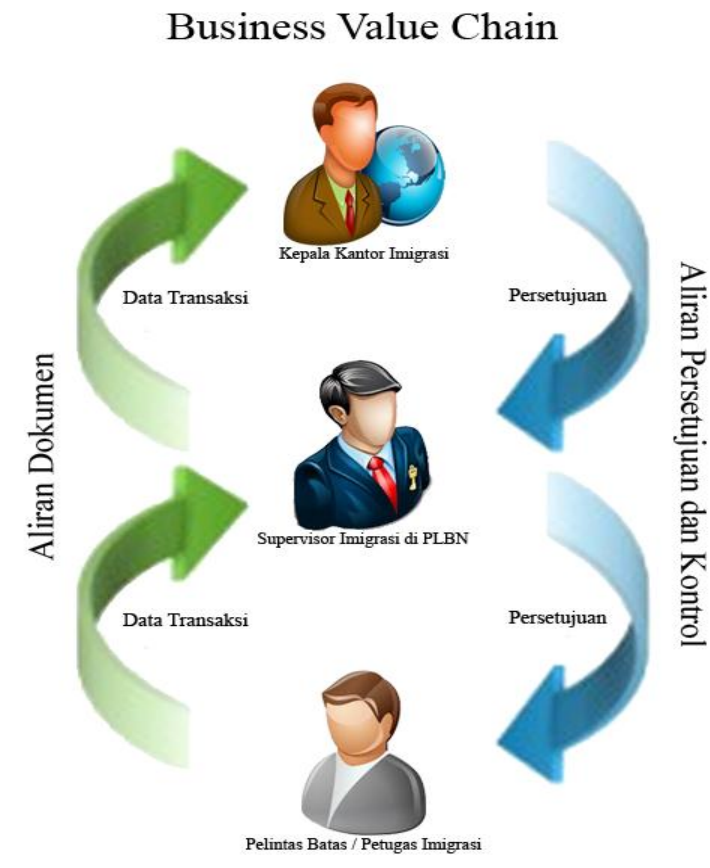

Gambar 4. Rantai nilai bisnis

Proses bisnis yang akan dijalankan melibatkan tiga (3) entitas yaitu para pelintas batas dan petugas imigrasi pada PLBN sebagai pengguna akhir dari sistem, supervisor imigrasi PLBN sebagai manajer tingkat menengah dan Kepala Kantor Imigrasi sebagai manajer tingkat atas.

Proses dimulai ketika para pelintas batas memasukkan data transaksi secara langsung melalui perangkat laptop/tablet/ponsel yang kemudian akan diperiksa oleh petugas dan supervisor kemudian disetujui oleh Kepala Kantor Imigrasi. Hal ini tentu mengurangi lama antrian pada layanan imigrasi di PLBN Terpadu. Sedangkan bagi pelintas yang tidak memiliki atau tidak mampu mengoperasikan perangkat laptop/tablet/ponsel akan dibantu oleh petugas imigrasi di PLBN Terpadu.

Pada proses bisnis yang dijalankan, aliran data mengalir dari entitas level bawah dalam hal ini adalah para pelintas batas dan petugas imigrasi menuju ke level di atasnya yaitu supervisor imigrasi dan akhirnya ke level 
teratas yaitu Kepala Kantor Imigrasi. Sebaliknya, data yang telah masuk akan diperiksa dan disetujui. Aliran approve atau persetujuan untuk melintasi batas wilayah negara berasal dari level paling atas menuju ke level paling bawah.

c. Perancangan aplikasi

Langkah pertama yang dilakukan dalam merancang aplikasi adalah perancangan arsitektur data, yaitu dengan menentukan kelas-kelas data yang dibutuhkan pada aplikasi.
Model yang digunakan dalam perancangan arsitektur data adalah class diagram yang tampak seperti pada gambar 5 .

Kelas-kelas data yang telah dirancang selanjutnya akan digunakan untuk beberapa aplikasi yang akan dibangun sesuai dengan kebutuhan otoritas imigrasi di PLBN Terpadu seperti yang dijelaskan pada tabel 2 berikut:

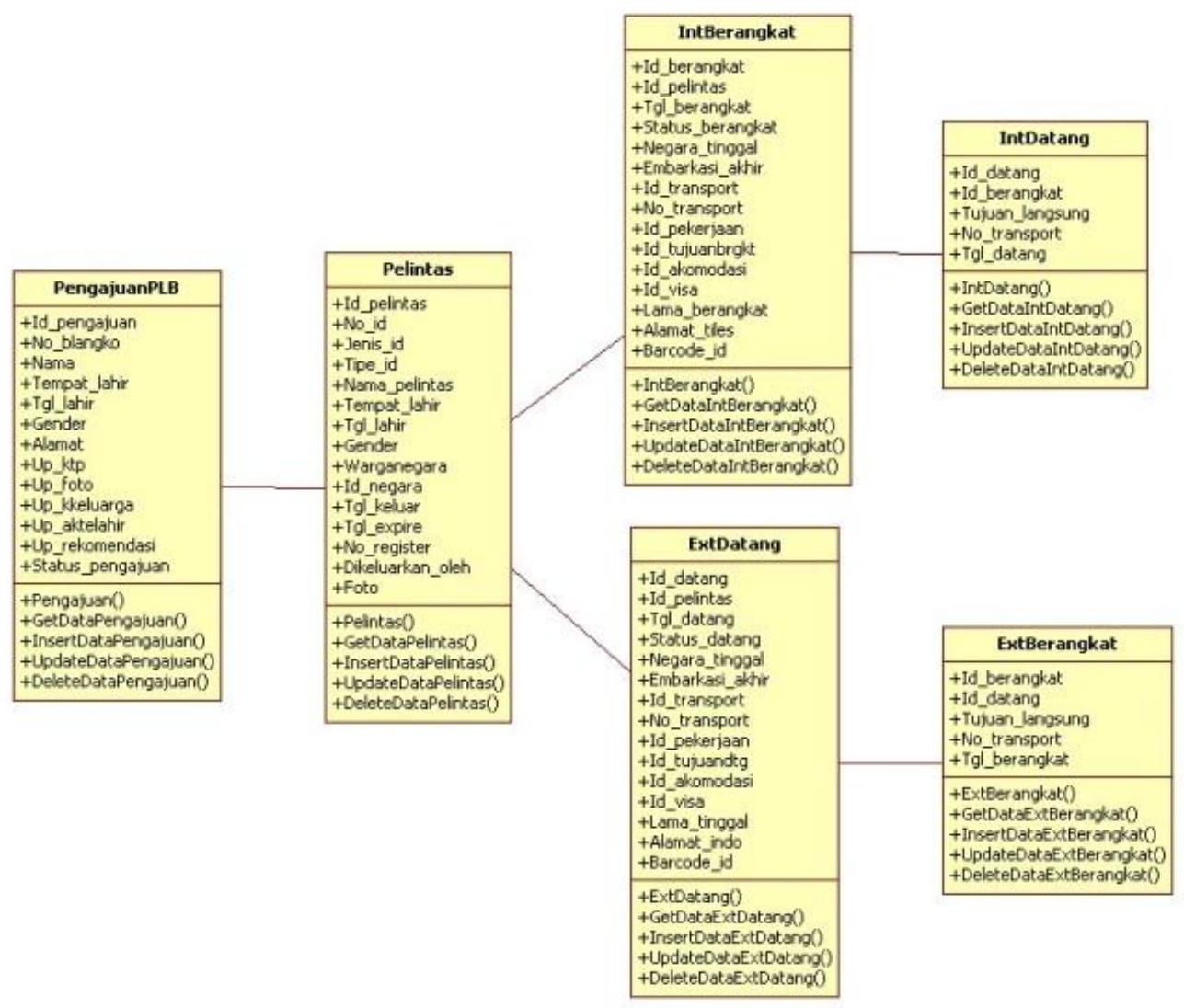

Gambar 5. Diagram kelas data

Tabel 2. Aplikasi pada sistem informasi

\begin{tabular}{|c|c|c|}
\hline No. & Nama Aplikasi & Fungsi \\
\hline 1 & $\begin{array}{l}\text { App.Paspor/ } \\
\text { PLB }\end{array}$ & Pendaftaran pengusulan PLB, pengelolaan data paspor maupun PLB. \\
\hline 2 & App.Perlintasan & $\begin{array}{l}\text { Pengelolaan data transaksi perlintasan, baik masuk maupun keluar } \\
\text { Indonesia.. }\end{array}$ \\
\hline 3 & App.Komunikasi & $\begin{array}{l}\text { Media komunikasi sosial, baik internal pihak keimigrasian (Kepala } \\
\text { Kantor, supervisor dan petugas) maupun dengan masyarakat umum. }\end{array}$ \\
\hline 4 & App.Monitoring & Pengontrolan terhadap lama waktu izin tinggal berdasarkan jenis visa. \\
\hline
\end{tabular}


d. Perancangan arsitektur teknologi

Arsitektur teknologi yang harus direncanakan adalah arsitektur teknologi jaringan, spesifikasi server, aplikasi maupun hardware. Pada penelitian ini, teknologi jaringan yang digunakan adalah model client server. Teknologi ini digunakan karena memiliki beberapa kelebihan antara lain bersifat multiplatform dan semua jenis pendataan serta pelaporan bisa langsung diperbaharui dan dapat diakses dari mana saja selama terdapat koneksi internet.

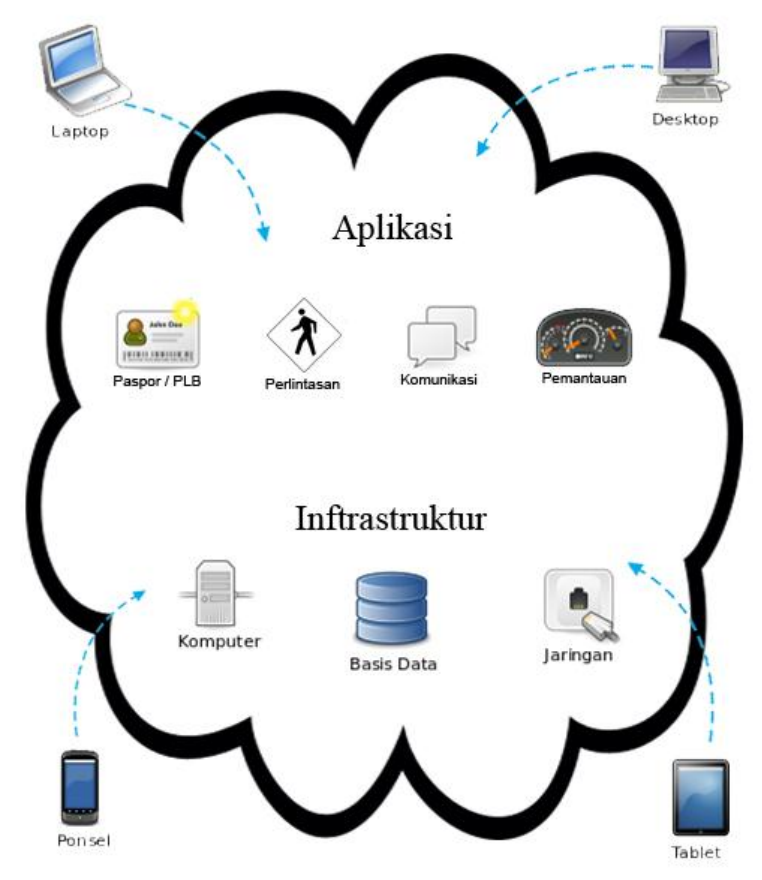

Gambar 6. Arsitektur teknologi yang direncanakan

Tampak pada gambar 6 bahwa semua data akan tersimpan pada basis data yang terpusat, oleh karena itu dibutuhkan sebuah server. Teknologi server yang digunakan untuk sistem informasi yang direncanakan harus memenuhi standar spesifikasi sebagaimana mestinya sebuah server, agar keamanannya terjaga dan memudahkan dalam proses pemeliharaan.

Adapun spesifikasi database yang diusulkan adalah MySql Server dan web server yang diusulkan adalah Apache/IIS. Perangkat lunak yang dibutuhkan untuk server adalah Windows Server 2016 sedangkan untuk client dapat menggunakan Windows, Linux atau Android sebagai sistem operasinya. Untuk kebutuhan perangkat keras disesuaikan dengan kebutuhan.

\section{KESIMPULAN}

Permasalahan keimigrasian yang kerap terjadi di wilayah kerja Kantor Imigrasi Kelas II Atambua, NTT disebabkan karena sistem dan infrastruktur yang masih terbatas sehingga berdampak pada kinerja yang belum maksimal dan proses bisnis yang tidak berjalan optimal.

Dengan merancang arsitektur sistem informasi keimigrasian berdasarkan kerangka PIECES dan TOGAF ADM dapat menghasilkan visi perencanaan arsitektur, perencanaan arsitektur bisnis, perencanaan arsitektur sistem informasi dan perencanaan arsitektur teknologi jaringan berbasis client server sesuai dengan permasalahan yang terjadi pada PLBN Terpadu di bawah naungan Kantor Imigrasi Kelas II Atambua, NTT dilihat dari berbagai dimensi yakni kinerja, informasi dan data, ekonomi, kontrol dan kemanan, efisiensi dan pelayanan.

Hasil akhir dari penelitian menunjukkan perlu adanya investasi baik perangkat keras maupun perangkat lunak untuk membangun infrastruktur yang baru agar dapat mendukung sistem yang akan diterapkan.

\section{UCAPAN TERIMA KASIH}

Ucapan terima kasih dan apresiasi diberikan kepada Drs. Paulus B. Manehat, M.Si sebagai Kepala Badan Pengelolaan Perbatasan Nusa Tenggara Timur dan Kurniadie S.H., M.H., sebagai Kepala Imigrasi Kelas II Atambua untuk dedikasi, dukungan, dan izinnya untuk melakukan penelitian di PLBN Terpadu. Apresiasi dan terima kasih juga diberikan kepada semua petugas imigrasi yang bertugas di PLBN Terpadu atas partisipasi mereka saat survey dan pengumpulan data.

\section{REFERENSI}

[1] Chircu, A., and Lee, D. 2003. "Understanding IT Investments In The Public Sector: The Case Of EGovernment'. Proceedings of the Ninth Americas Conference on Information Systems. Florida, December 31, 792-800.

[2] Rocheleau, B., and Wu, L. 2002. "Public Versus Private Information System: Do 
They Differ In Important Ways? A Review And Empirical Test". American Review of Public Administration 32. 4, 379-397.

[3]Farnham, D., and Horton, S. (1996). Managing The New Public Services. UK: Palgrave Macmillan.

[4]Kamal, M.M. 2006. "IT Innovation Adoption In The Government Sector: Identifying The Critical Success Factors". Journal of Enterprise Information Management 19. 2, 192-222.

[5]Efendi. 2014. "Studi tentang pelayanan publik Pas Lintas Batas (PLB) KrayanBa'kelalan Malaysia di Kantor Imigrasi Kecamatan Krayan Kabupaten Nunukan". eJournal Ilmu Administrasi Negara 3. 2, 613-627.

[6] El-Sawy, O. (2001). Redesigning Enterprise Processes For e-Business. New York: McGraw-Hill Education.

[7]Suhendri. 2016. "Perancangan Arsitektur Sistem Informasi Sekolah Dengan The Open Group Architecture Framework (TOGAF) (Studi Kasus: Pondok Pesantren Ar-Rahmat)". Infotech Journal 1. 2, 40-47.

[8]Suryadi dan Andry, J.F. 2017. "Perancangan Enterprise Architecture Mengunakan TOGAF Architecture Development Method (Studi Kasus: Yakuza Gym Jakarta Barat). Seminar Nasional Teknoka 2, Jakarta, November 4, 29-34.
[9]Sutabri, T. (2012). Konsep Sistem Informasi. Yogyakarta: Andi Publisher.

[10]Yakub. (2012). Pengantar Sistem Informasi. Yogyakarta: Graha Ilmu.

[11]Whitten, J. L., and Bentley, L. D. (2007). Systems Analysis And Design Methods Paperback. New York: McGraw-Hill.

[12]Dube, M.R., and Dixit, S.K. 2011. "Comprehensive Measurement Framework For Enterprise Architectures". International Journal of Computer Science \& Information Technology (IJCSIT) 3. 4, 71-92.

[13]The Open Group. (2009). The Open Group Architecture Framework (TOGAF), Version 9, Evaluation Copy, Document Number: G091. San Francisco: The Open Group.

[14]Proper, E., and Greefhorst, D. 2011. "Principles In An Enterprise Architecture Context". Journal of Enterprise Architecture 7. 1, 8-16.

[15]Yunis, R., dan Surendro, K. 2009. "Perancangan Model Enterprise Architecture Dengan Togaf Architecture Development Method". Jurnal Seminar Nasional Aplikasi Teknologi Informasi (SNATI) 6, Yogyakarta, Juni 20, 25-31.

[16]Menchaca, A.G.V., et al. 2013. "Practical Application Of Enterprise Architecture, Study Case Of SME Metalmechanic in Mexico". European Scientific Journal 1, 233-241. 